M. J. S. Poliakow, of the Russian Geographical Society, is about to commence his researches in the government of Vladimir and in Lithuania into the remains of the stone period. This expedition is in continuation of the labours of .M. Poliakow, commenced more than ten years ago by the discovery of imple ments of stone in the plane of the river Irkout (1867). Later, in $187 \mathrm{I}$, he found implements of the same kind in the government of Olonets, on the banks of Lakes Lago, Kenozero, \&c. ; in 1874 he found them also on the banks of the lakes of the upper basin of the Volga; and lastly, the journey which he undertook in 1876 , in the valley of the Obi, convinced him not only of the existence of remains of the stone period in Western Siberia, but led him to seek the explanation of many stone implements among the implements of peoples possessing only a low degree of culture, as among the Ostialss. This series of journeys has enabled M. Poliakow to form a very considerable collection of implements in stone and of curious data on the natural history of that epoch. Now, new discoveries have been made by other travellers in the districts of Mourom, Vladimir, and in Esthonia, on the banks of Lake Bourtnek, where a tumulus has been discovered containing remains of objects connected with cookery. All these discoveries have led M. Paliakow to request the Snciety to send him into the government of Vladimir and into Esthonia, to study upon the spot these new remains. What attracts the attention of $M$. Poliakow is that there are, among other things, proofs that, during the stone period, there existed in the small fresh-water lakes a species of seal recalling, by its dimensions and charac. teristics, the seal of Greenland and the Caspian. Another remarkable fact is the discovery made, along with the instruments of stone in the district of Mourom, remains of the mammoth. After having investigated the materials referred to, M. Poliakow proposes to visit Stockholm, Copenhagen, and other cities, to inspect the pre-historic museums, with a view to complete the materials he possesses for studying the stone period.

Dr. Schomburgk, in his Report on the Botanic Garden and Government Plantations of South Australia for 1877 , gives an account of an interesting experiment he made with some Arctic wheat. He received a sample of wheat taken from a quantity left by the American Arctic Expedition ship Polaris in $187 \mathrm{I}$, which had been abandoned in north latitude $81^{\circ} 16^{\prime}$. This wheat had been left on the beach exposed to the snow and a temperature of $72^{\circ}$ to $104^{\circ}$ of frost for five years, and was found in a heap by Dr. Ninnis, of H.M. ship Discovery, on the return of the last Arctic Expedition to England. Dr. Schomburgk received I, ooo grains, of whicl he sowed about 300 . From the 300 grains about sixty germinated. The plants grew healthy and reached to the height of from three to four feet. It is a bearded wheat, and ripened in the commencement of January. The ears contained about thirty grains each, which were but small, though round and plump. The birds unfortunately destroyed the greater part before it came to maturity, but the interesting fact proves the assertion that the grain of the cereals possesses a vitality not surpassed by any other seed.

Tin additions to the Zoological Society's Gardens during the past week include a Japanese WoIf (Canis hodophylax) from Japan, presented by Mr. H. Heywood Jones; a Rhesus Monkey (Macacus Erythrous) from India, presented by Mrs. Walcot; a Brown Capuchin (Cebus fatuelluss), a Crested Curassow (Crax alector) from Venezuela, presented by $\mathrm{Mr}$. A. Warmington; a Moin Monkey (Cercopithecus mona) from West Africa, presented by Capt. C. F. Filliter; a Green Monkey (Cercopithecus callitrichus) from West Africa, presented by Mrs. George Yeomens; a Common Marmoset (Hapale jacchus) from South East Brazil, a Pinche Monkey (Midars ardipus) from New Granada, presented by Mr. Edward Clayton; a Bonnet Monkey
(Macacus radiatzs) from India, presented by Mr. Allen Forbes; a Short-Tailed Capromy (Capromys brachyurus) from Jamaica presented by the Hon. J. Burford Hancock; a Pine Marte, (Martes abietzm) from Ireland, presented by Mr. Robert Walter; six Groldfinches (Carduelis clegans) British Isles, a Common Chameleon (Chamaleon vulgraris) from North Africa, presented. by Mr. C. F. Johnson; four Cunningham's Skinks (Egernia cunninghaniii) from Australia, presented by Mr. D. C. Pearson; a Garden's Night Heron (Nycticorax gardeni), a Common Boa (Boa constrictor) from South America, purchased; a Greennecked Peafowl (Pavo spicifer) bred in the Gardens.

\section{A NEW GALVANOMETER FOR LECTURE PURPOSES}

$A$ LL who have had the experience of attempting to exhibit to a large audience the simple phenomena of dynamical electricity will bear testimony to the difficulty of rendering apparent over the whole of a lecture-theatre the movements of a galva. nometer needle. When the galvanometer lies flat upon the table and the movements of the needle itself, or of the index attached to it are observed, the number of observers must be confined to those near at hand. Even the mirror galvanometer, indispensable as it is for delicate experiments, is open to the objection that a popular audience does not immediately appreciate the significance of the motions of the wandering spot of light. The devices for projecting the moving needle upon the screen have, up to the present time, been so large and inconvenient as to militate against their use for popular demonstration.

These facts led the writer some months ago to attempt to construct an instrument for projection upon the screen that should be within the size of an ordinary magic-lantern slide. The early attempts to do this were unpromising, and possessed little sensitivity even for considerable currents. In the latest form of the instrument, however, this defect has been overcome, and the galvanometer has in several trials before large popular audiences, as well as in the teaching of the lecture-room, shown itself to

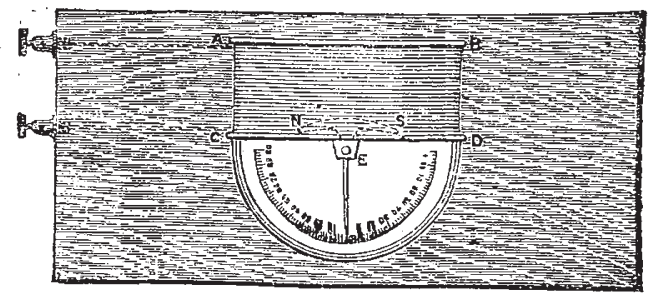

answer with complete satisfaction the purposes for which it was designed.

In the most improved form, the galvanometer consists of a mahogany block the size and thickness of an ordinary magic lantern slider, which serves as a frame to contain the working parts. The coil of wire is wound upon a flat bobbin of brass or ivory, its ends being brought to a pair of terminals at the extremity of the slider. Within the coil the magnetised needle is suspended delicately by a horizontal axis between two adjustable screws. Attached at right angles to the needle is a light index of thin brass or of aluminium. The scale, which is transparent, is reduced by photography upon a glass plate. The arrangements are therefore on a small scale like those of a Becquerel's vertical galvanometer inverted. When no current passes, the index arm hangs downward, the centre of gravity being adjusted very little below the centre of suspension so as to secure the greater degree of sensitivity. But to correct for the dip when the plane of the instrument is nearly in the meridian a small compensating magnet may be placed upon the table below. Thus the slightest movement of the needle is at once made visible by the motion of the magnified image of the scale and index; and will be quite apparent even without lowering the lights of the room.

As the instrument may be constructed with either a short-coil or a long-coll, it can be appliedito a variety of experimental uses. And its portability and simplicity exceed those of any galvanometer hitherto employed for purposes of demonstration.

Silvanus P. Thompson 